\title{
Gestão socioambiental na administração pública: uma análise de instrumentos legislativos aplicáveis ao âmbito institucional
}

\author{
Marcos Rek ${ }^{1}$ \\ Marcos Junior Marini
}

\begin{abstract}
Resumo: A problemática ambiental tornou-se evidente a partir da década de 1960, e, desde então, tomaram corpo os debates e movimentos mundiais com vistas à sustentabilidade ambiental. Nesta discussão, é indispensável a adoção de ações que minimizem os impactos e a degradação ambiental, inclusive com o envolvimento do poder público, o qual deve implementar políticas efetivas à gestão socioambiental na administração pública no Brasil. Assim, o presente estudo objetivou, por meio de pesquisa documental, identificar os principais instrumentos legais de gestão socioambiental e respectivos dispositivos aplicáveis ao âmbito interno na administração pública brasileira. Inferiu-se que há um arcabouço legislativo capaz de fornecer alternativas à minimização de impactos ambientais no âmbito interno públiç; entrementes, a gestão socioambiental somente poderá efetivar-se com ações que ultrapassem o aspecto burocrático das leis, com a adoção de posturas comprometidas e ampla participação social.
\end{abstract}

Palavras-chave: Crise ambiental. Gestão socioambiental. Administração pública brasileira.

Abstract: Environmental issues became evident from the 1960s on, and since then, global debates and movements have taken shape with a view to environmental sustainability. In this discussion, it is indispensable to adopt actions that minimize impacts and environmental degradation, including the involvement of the public power, which must implement effective policies for social and environmental management in public administration in Brazil. Thus, the present study aimed, through documentary research, to identify the main legal instruments of social and environmental management and respective devices applicable to the internal scope in the Brazilian public administration. It was inferred that there is a legislative framework capable of providing alternatives to the minimization of environmental impacts in the public internal environment meanwhile socio-environmental management can only be carried out with actions that go beyond the bureaucratic aspect of the laws, with the adoption of compromised and broad social participation.

Keywords: Environmental crisis. Socio-environmental management. Brazilian Public Administration.

\section{Introdução}

A problemática ambiental teve como marco mais significativo a Revolução Industrial, tornando-se evidente essencialmente a partir da década de 1960. A partir de então, a preocupação global com os impactos visíveis e as ameaças iminentes tomou corpo, bem

\footnotetext{
${ }^{1}$ Mestre em Desenvolvimento Regional. Servidor público do TRE-PR. marcosrek@yahoo.com.br

${ }^{2}$ Doutor em Tecnologia. Professor do Programa de Pós-Graduação em Desenvolvimento Regional (PPGDR) da Universidade Tecnológica Federal do Paraná (UTFPR) Campus - Pato Branco. marini@utfpr.edu.br
} 
como os movimentos ambientais mundiais, visando à obtenção de alternativas à sustentabilidade ambiental.

Para além dos aspectos positivos, caracterizados pela consciência ambiental em nível macro, é indispensável a transposição do debate teórico para a adoção e incorporação de práticas que minimizem os impactos e a degradação ambiental decorrentes da ação antrópica, o que deve ocorrer efetivamente em nível micro, com a regionalização e individualização de iniciativas socioambientais, inclusive com o envolvimento de organizações na esfera pública. Para que estas práticas se tornem efetivas, contudo, transitando do aspecto teórico para o prático, são necessárias ferramentas para a operacionalização de ações, materializando-se por meio de instrumentos de gestão socioambiental.

Neste ponto, fundamentalmente, o presente artigo tem como desiderato o estudo das ferramentas específicas aplicáveis à gestão socioambiental no Brasil, e, assim, procura evidenciar os principais instrumentos legislativos de caráter socioambiental exarados e aplicáveis ao âmbito interno da administração pública federal, com vistas à mitigação dos respectivos impactos negativos gerados.

Destarte, nesta tratativa, além dessas considerações iniciais, o presente artigo compreende as seguintes seções: 2 - A crise Ambiental e a Gestão Socioambiental; 3 Metodologia adotada no estudo; 4 - Resultados e Discussões, com destaque aos mais relevantes instrumentos e dispositivos consubstanciados pela legislação federal, aplicáveis à gestão socioambiental no âmbito interno da administração pública federal; e as Considerações Finais.

\section{A crise ambiental e a gestão socioambiental}

Inicialmente, para o embasamento deste trabalho, apresenta-se uma breve fundamentação sobre as temáticas referentes à crise ambiental e os mais relevantes aspectos relativos à gestão socioambiental pública, adentrando-se subsequentemente, à identificação e caracterização dos principais instrumentos socioambientais com base no arcabouço legislativo federal. 


\title{
2.1 A crise ambiental
}

O presente século trouxe consigo, para a sociedade mundial contemporânea, uma herança em caráter irrenunciável, deixada, principalmente, pela racionalidade econômica e industrial do século passado: a crise ambiental.

Os reflexos desta crise não provêm exclusivamente do período mencionado. Conforme Moran (2011), desde a Revolução Industrial, os impactos e o seu ritmo têm se ampliado gradualmente, tornando-se ainda mais sensíveis nos últimos 60 anos, principalmente para o atendimento das crescentes demandas e padrões de consumo de bens e serviços, com os consequentes aumentos da extração de recursos naturais, a produção de resíduos, emissões atmosféricas, poluição e degradação ambiental (SEIFFERT, 2014).

Do processo de exploração da natureza e do homem, diversos são os reflexos consabidos. Moran (2011) ressalta sobre o "[...] aumento exponencial do dióxido de carbono, as taxas exponenciais da redução do ozônio e das concentrações de óxido nitroso na atmosfera, a perda acelerada das florestas tropicais, o aumento na frequência dos desastres naturais e da extinção das espécies" (MORAN, 2011, p. 30-31).

Leff, no concernente às consequências sociais, discorre:

\begin{abstract}
Nunca antes na História houve tantos seres humanos que desconhecessem tanto e estivessem tão excluídos dos processos e das decisões que determinam suas condições de existência; nunca antes houve tanta pobreza, tanta gente alienada de suas vidas, tantos saberes subjugados, tantos seres que perderam o controle, a condução e o sentido de sua existência; tantos homens e mulheres desempregados, desenraizados de seus territórios, desapropriados de suas culturas e de suas identidades (LEFF, 2011, p. 312).
\end{abstract}

Neste contexto, diante destes reflexos e riscos socioambientais, a primeira consideração a ser assumida é a de que "[...] os problemas ambientais de grande consequência da agenda contemporânea [...], são, presumivelmente, produto de atividades humanas e têm origem social" (FLORIT, 1998, p. 63).

Para além de outras teorias, a crise ambiental pode ser entendida como consequência de uma postura antropocêntrica, na qual, “[...] a ideia monoteísta, a invenção de um Deus único e invisível, da imutabilidade do tempo na reencarnação e na transcendência [...] foi transferida para o campo do conhecimento como um logos regente 
do mundo" (LEFF, 2010, p. 194), o que ocasionou um deslocamento da perspectiva teocêntrica para aquela em que o homem passou a considerar-se a referência central.

Essa postura provocou um distanciamento e hierarquização entre o ser humano e a natureza, passando o homem a agir como se estivesse "[...] acima das regras que regem as demais espécies do planeta" (MORAN, 2011, p. 32), gerando a separação entre o homem e a natureza, e a visão "coisificada" do mundo, na qual a natureza deve ser controlada e explorada para os propósitos humanos (LEFF, 2010; MORAN, 2011).

Por outra via, conforme alguns autores (LEFF, 2010; GUIMARÃES, 2001), é possível constituir tal cenário como uma crise do conhecimento ou uma crise da civilização. Para Leff, a verdadeira crise dos tempos atuais é uma crise do pensamento ocidental, ou de conhecimento:

[...] da "determinação metafísica" que, ao pensar o ser como ente, abriu o caminho para a racionalidade científica e instrumental que produziu a modernidade como uma ordem coisificada e fragmentada, como formas de domínio e controle sobre o mundo. Por isso, a crise ambiental é acima de tudo um problema de conhecimento [...] (LEFF, 2010, p. 191).

Guimarães (2001), por sua vez, menciona que a problemática ambiental é gerada por uma crise da civilização, que corresponde ao "[...] esgotamento de um estilo de desenvolvimento ecologicamente depredador, socialmente perverso, politicamente injusto, culturalmente alienado e eticamente repulsivo" (GUIMARÃES, 2001, p. 51). Do exposto acima, consubstancia-se a percepção distinta da crise ambiental como uma crise da civilização, ou uma crise do conhecimento, tendo por gênese, essencialmente, o antropocentrismo, que passou a conduzir a dicotômica relação entre a natureza e o homem.

Com os evidentes reflexos da exploração econômica sobre os recursos naturais, manifestados por meio das perceptíveis consequências ambientais e sociais, constitui-se efetivamente a problemática da crise ambiental, a partir do que passaram a tomar corpo as discussões em nível mundial, a atuação de diversos atores sociais, os movimentos e instituições ambientalistas e os debates referentes ao desenvolvimento sustentável ${ }^{3}$.

\footnotetext{
3 O termo "desenvolvimento sustentável" teve sua origem no relatório Nosso Futuro Comum, conhecido como Relatório de Brundtland, da Comissão Mundial sobre o Meio Ambiente e Desenvolvimento (CMMAD,1991), o qual, definitivamente dissemina o conceito (SILVA, 2012) como "um processo que permite satisfazer as necessidades da população atual sem comprometer a capacidade de atender as gerações futuras" (LEFF, 2001, p. 19).
} 
Para além de uma falsa retórica, primeiramente é necessário eliminar o paradigma antropocêntrico, assumindo uma nova óptica em relação à natureza, que se constrói com uma "nova ética do desenvolvimento", na qual os objetivos econômicos do progresso estejam subordinados às leis da natureza, ao respeito à dignidade humana e à melhoria de qualidade de vida das pessoas (GUIMARÃES, 2001, p. 55).

Esta nova ética compreende um novo estilo de desenvolvimento, que seja:

[...] "ambientalmente" sustentável no acesso e no uso dos recursos naturais e preservação da biodiversidade; socialmente sustentável na redução da pobreza e das desigualdades sociais e promotor da justiça e da equidade; "culturalmente" sustentável na conservação dos sistemas de valores, práticas e símbolos de identidade [...] "politicamente" sustentável ao aprofundar a democracia e garantir o acesso e a participação de todos nas decisões de ordem pública (GUIMARÃES, 2001, p. 55).

Abre-se, assim, um diálogo entre novos atores sociais e práticas coletivas para a reapropriação da natureza e para um processo compromissado com a sustentabilidade socioambiental (JACOBI, 2003; LEFF, 2012).

Neste debate, dentre os diversos atores sociais, insere-se o poder público, que, em face de suas atribuições, configura-se como protagonista, derivando-Ihe, assim, o dever de implementar políticas públicas, materializadas por meio de instrumentos legais e normativos específicos, em processos de gestão socioambiental da administração pública.

\subsection{Gestão socioambiental: aspectos conceituais}

A crise ambiental e os respectivos conflitos gerados (forças motoras) demandam ações coordenadas de diversos agentes (decisores), como a sociedade civil, indivíduos e governos, visando à solução de conflitos socioambientais e a compatibilização das atividades humanas com a qualidade e preservação do patrimônio ambiental, processo denominado de gestão socioambiental (BRAGA et al. 2005; SEIFFERT, 2014; SABBAGH, 2011).

De acordo com Seiffert, "[...] o processo de gestão ambiental surgiu como uma alternativa para buscar a sustentabilidade dos ecossistemas antrópicos, harmonizando suas interações com os ecossistemas naturais" (SEIFFERT, 2014, p. 45), porém, ressalta a autora, tal harmonização se constitui complexa, visto que envolve interesses conflitantes em relação ao meio ambiente. 
Diante do preocupante cenário ambiental, intensificaram-se a conscientização e as pressões sociais, visando a um ambiente ecologicamente equilibrado, derivando daí a obrigação e a necessidade de adoção e implementação de políticas socioambientais.

Braga et al. (2005) asseveram que a gestão do ambiente compreende diversas fases, iniciando-se com a identificação de valores envolvidos nos conflitos ambientais e o estabelecimento de políticas públicas ambientais, o que engloba "[...] a identificação dos objetivos, a conceituação e a institucionalização do sistema de gestão e dos instrumentos econômico-financeiros, legais e técnicos que o compõem" (BRAGA et al., 2005, p. 220).

Segundo Seiffert (2014), para que a gestão ambiental possa ser incorporada a organizações, fazem-se necessárias ações e posturas estratégicas, o que pressupõe e compreende a existência de quatro componentes distintos: 1) elaboração e instituição de uma política ambiental; 2) desenvolvimento de um planejamento; 3) gerenciamento ambiental; e, 4) monitoramento ambiental.

A partir desta percepção e da urgência na adoção de alternativas sustentáveis, instrumentos específicos de gestão socioambiental passaram a ser desenvolvidos na esfera pública, ou seja, políticas públicas ambientais de caráter regulador, consubstanciadas por leis e normatizações específicas emanadas pelo Estado em face de seu poder/dever.

Os instrumentos de gestão ambiental constituem-se ferramentas destinadas à instituição de práticas socioambientais no âmbito organizacional, tanto na esfera pública como na privada. É por meio desses instrumentos que se torna possível a materialização de ações, atividades, projetos, programas e políticas públicas com vistas à sensibilização dos diversos atores envolvidos no processo, para a minimização, ou supressão da degradação e dos impactos ambientais negativos e para a ampliação da qualidade de vida.

Na esfera pública brasileira, a implementação da gestão socioambiental, a exemplo de todo e qualquer ato exarado pela administração, deve guiar-se por princípios específicos que regem a sua atuação, fundamentalmente, neste caso, pelo princípio constitucional da legalidade. Dentre outros princípios, o da legalidade vem consagrado na Constituição Federal de 1988, em seu artigo 37, o qual estabelece que "[...] a administração pública direta e indireta de qualquer dos Poderes da União, dos Estados, do Distrito Federal e dos Municípios obedecerá aos princípios de legalidade, impessoalidade, moralidade, publicidade e eficiência [...]" (BRASIL, 1988). 
Conforme apontam os autores Alexandrino e Paulo (2009), infere-se da legalidade que a "Administração Pública somente tem possibilidade de atuar quando exista lei que o determine (atuação vinculada) ou autorize (atuação discricionária), devendo obedecer estritamente ao estipulado na lei [...]" (ALEXANDRINO; PAULO, 2009, p. 196). Assim, é dado ao poder público agir exclusivamente de acordo com os ditames preceituados na Constituição Federal, em leis e demais normativos, do que deriva a necessidade de a administração estar atenta aos critérios legais, inclusive quanto à elaboração e à efetiva implantação da gestão socioambiental pública.

A gestão socioambiental, na esfera pública, depende da implementação de políticas públicas, nas quais sejam definidas estratégias, ações, investimentos e providências institucionais e jurídicas, que têm a finalidade de garantir a qualidade do meio ambiente, a conservação da biodiversidade e o desenvolvimento sustentável, por meio de mecanismos de imposição denominados instrumentos de gestão ambiental pública - legislação e regulamentos socioambientais específicos (BRAGA et al., 2005; SEIFFERT, 2014).

Os instrumentos de gestão ambiental pública derivam da obrigação de atender aos comandos normativos e legais emanados pelo poder público, orientados ao controle de atividades e ações individuais ou coletivas, denominados instrumentos de comando e controle, os quais, conforme Seiffert:

Baseiam-se na criação e implantação de políticas públicas, as quais, para serem operacionalizadas, devem ser desdobradas em itens legais nos mais diversos níveis (municipal, estadual e federal). São mecanismos de imposição que se constituem na primeira geração de instrumentos de gestão ambiental (SEIFFERT, 2014, p. 59).

A gestão socioambiental, ademais, além de refletir essencialmente na perspectiva ambiental, deve também incorporar a perspectiva social, com a elaboração e implementação de políticas socioambientais efetivas, editadas a partir das demandas ambientais da sociedade, garantindo-se a democrática participação popular em todas as fases de suas elaborações, alicerçadas na justiça ambiental:

A noção de justiça ambiental implica o direito a um meio ambiente seguro, sadio e produtivo para todos, onde o "meio ambiente" é considerado em sua totalidade, incluindo suas dimensões ecológicas, físicas construídas, sociais, políticas, estéticas e econômicas (ACSELRAD; MELLO, BEZERRA, 2009, p. 16). 
Com a análise desta subseção, efetiva-se a teorização que possibilita a adequada abordagem subsequente, adentrando-se, assim, na especificação dos aspectos metodológicos adotados neste estudo.

\section{Metodologia}

O presente trabalho adotou como procedimento metodológico a pesquisa documental, por meio do acesso às páginas (web sites, home pages) institucionais e governamentais, na internet, principalmente na busca de documentos legislativos das seguintes instituições: Palácio do Planalto, Ministério do Meio Ambiente e Ministério do Planejamento, Orçamento e Gestão do Governo Federal do Brasil.

Para o cumprimento do objetivo, realizou-se uma pesquisa e coleta de documentos oficiais (leis e normativos no âmbito federal) que contemplam a inserção de critérios socioambientais na esfera pública, ressaltando-se que a perspectiva adotada na análise desses documentos é a interna, ou seja, os instrumentos exarados para implementação das políticas socioambientais na administração pública brasileira. A partir da compilação dos referidos documentos, procedeu-se à análise de cada um daqueles normativos, no intuito de identificar e filtrar os dispositivos legais concernentes às práticas e políticas de caráter socioambiental de aplicação interna ao setor público, os quais foram transcritos nas respectivas seções.

Neste contexto, a próxima seção apresenta os resultados obtidos e respectivas discussões, com a identificação das características específicas do arcabouço legislativo correlacionado à gestão socioambiental pública.

\section{Resultados e discussões}

Esta seção relaciona os resultados obtidos na pesquisa documental, evidenciando-se os principais instrumentos de comando e controle exarados no âmbito legislativo federal, consubstanciados por meio de leis, normas e regulamentações federais. Estes contemplam critérios de inserção de práticas à gestão socioambiental na administração pública no aspecto institucional interno. 
A pesquisa tem como marco inicial a instituição da Política Nacional de Meio Ambiente, ocorrida em 1981, por meio da Lei Federal no 6.938. Desde então, seguiram-se as regulamentações no sentido de implementar instrumentos hábeis à redução ou supressão dos impactos ambientais derivados das atividades da máquina administrativa pública. Da busca efetuada, compilaram-se os instrumentos legislativos elencados no gráfico abaixo, os quais são correlacionados ao período de sua edição e publicação.

Figura 1 - Principais instrumentos legislativos socioambientais aplicáveis à Gestão Pública

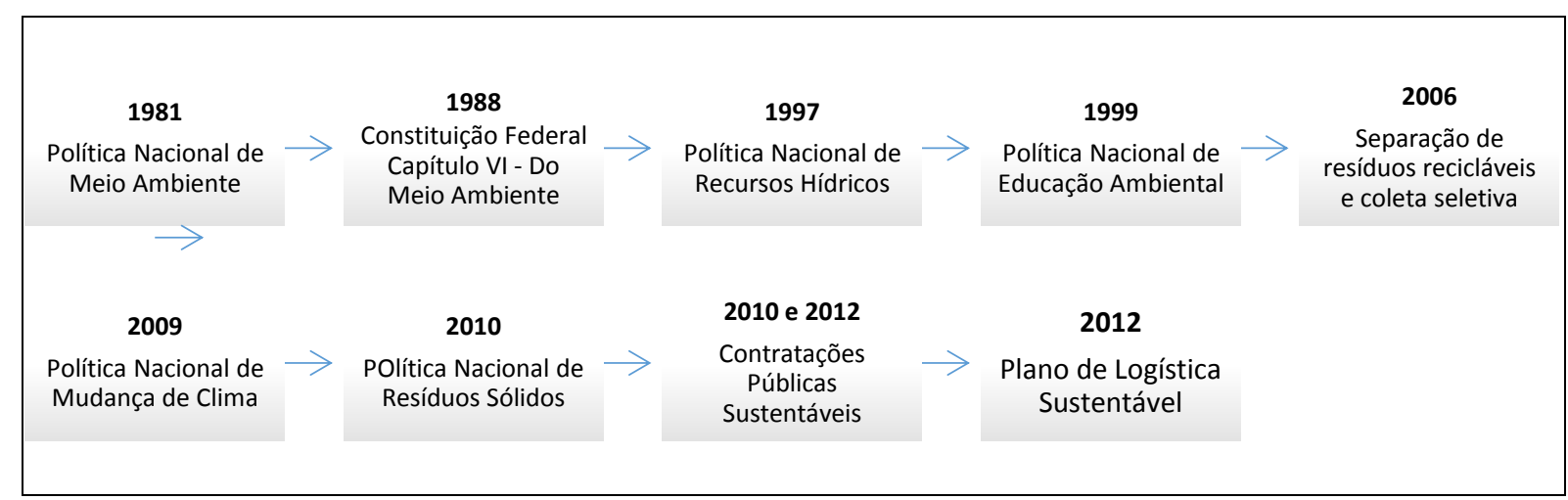

Fonte: Elaborado pelos autores.

Os normativos sintetizados na Figura 1 ditam as diretrizes gerais que orientam a adoção de iniciativas socioambientais na esfera pública. Assim, dá-se sequência, nas próximas subseções, à análise e contextualização das características socioambientais observadas em cada um desses instrumentos legais e respectivos dispositivos, pertinentes e aplicáveis internamente à gestão pública brasileira.

\subsection{A Política Nacional de Meio Ambiente: marco legal inicial}

Nesta trajetória em que se recorre à especificação dos mais evidentes normativos ambientais, é indispensável relacionar como marco legal inicial ${ }^{4}$ a denominada Política Nacional de Meio Ambiente - Lei no 6.938/1981, considerado um documento de vanguarda, visto que, à época de sua edição, já consagrava importantes definições e instrumentos

\footnotetext{
${ }^{4}$ A Política Nacional do Meio Ambiente "[...] constituiu o marco inicial das ações para conservação ambiental e incorporação do tema nas atividades de diversos setores da sociedade. A partir daí, várias normas e regulamentações passaram a disciplinar a questão ambiental, relacionadas à conservação do meio ambiente, uso dos ecossistemas, educação ambiental, água, patrimônio genético, fauna e flora, entre outras" (MMA, 2009, p. 11).
} 
regulatórios ambientais, muito antes da promulgação da Constituição de 1988. Esta lei, além de criar o Sistema Nacional de Meio Ambiente (SISNAMA) - e o Conselho Nacional do Meio Ambiente (CONAMA) com suas respectivas atribuições e competências, apresenta em seu art. 3o breves definições sobre meio ambiente, degradação ambiental, poluição e recursos ambientais. Ademais, em seu artigo 4으, detalha os objetivos da Política Nacional de Meio Ambiente (BRASIL, 1981).

Dispositivo a ser ressaltado da lei em comento é o art. 5ㅇ, o qual relaciona a necessidade de elaboração de diretrizes a serem materializadas em normas e planos para orientar a ação dos governos da união, estados, distrito federal e municípios, com vistas à preservação da qualidade ambiental e do equilíbrio ecológico. Esse artigo, inclusive, deverá ser aplicável às atividades empresariais públicas e privadas (BRASIL, 1981), deixando evidente uma primeira manifestação quanto à obrigatoriedade de adoção de critérios ambientais no âmbito administrativo público.

Ademais, dentre outros aspectos, no artigo 9ㅇ, destacam-se os instrumentos da Política Nacional de Meio Ambiente, valiosas ferramentas aplicáveis pelo poder público à regulação, controle e fiscalização ambiental, tais como o zoneamento ambiental, a avaliação de impactos ambientais, o licenciamento de atividades efetiva ou potencialmente poluidoras, a criação de áreas de proteção ambiental. Essas penalidades são aplicáveis pelo não cumprimento de medidas destinadas à preservação ou correção da degradação ambiental, e, ainda, entre outras, a garantia da prestação de informações relativas ao meio ambiente pelo poder público (BRASIL, 1981).

Constata-se a expressividade da Lei no 6.938/81, visto que foi recepcionada pela Constituição Federal de 1988, aproximadamente 36 anos após sua edição. Com algumas alterações, encontra-se em plena vigência, atendendo às demandas normativas ambientais contemporâneas, configurando-se como primeiro instrumento a exigir do setor público a adoção de planos e diretrizes ambientais.

\subsection{A Constituição Federal de 1988 e o meio ambiente}

Um segundo marco fundamental da questão ambiental no Brasil dá-se com a promulgação da Constituição da República Federativa do Brasil em 1988. Num contexto de 
redemocratização e atenta aos direitos difusos, dedicou um capítulo exclusivo à tratativa sobre o meio ambiente. Esta Constituição foi a primeira a trazer, "[...] de modo específico e global, inclusive em capítulo próprio, regras sobre o meio ambiente, além de outras garantias previstas de modo esparso na Constituição" (LENZA, 2009, p. 848), configurando-se, assim, o preservacionismo ambiental, como leciona o mesmo autor, como um direito humano de terceira dimensão, no qual se insere a coletividade, dando origem aos direitos de solidariedade.

A CF/1988 estabelece em seu artigo 225, caput, que todos têm direito ao meio ambiente ecologicamente equilibrado, contudo assevera que se impõe ao poder público e à coletividade o dever de defendê-lo e preservá-lo para as presentes e futuras gerações (BRASIL, 1988). Evidente do transcrito, como esclarece Lenza (2009), que o dever de preservação é do Estado e da coletividade, visto que o meio ambiente não é um bem privado ou público, mas um bem de natureza difusa, de uso comum do povo, um direito que pertence a cada indivíduo, à sociedade e às futuras gerações.

Para que o direito seja contemplado, o parágrafo 10 do artigo 225 elenca ao poder público um rol de atribuições:

\footnotetext{
I - preservar e restaurar os processos ecológicos essenciais e prover o manejo ecológico das espécies e ecossistemas;

II - preservar a diversidade e a integridade do patrimônio genético do País e fiscalizar as entidades dedicadas à pesquisa e manipulação de material genético;

III - definir, em todas as unidades da Federação, espaços territoriais e seus componentes a serem especialmente protegidos, sendo a alteração e a supressão permitidas somente através de lei, vedada qualquer utilização que comprometa a integridade dos atributos que justifiquem sua proteção;

IV - exigir, na forma da lei, para instalação de obra ou atividade potencialmente causadora de significativa degradação do meio ambiente, estudo prévio de impacto ambiental, a que se dará publicidade;

V - controlar a produção, a comercialização e o emprego de técnicas, métodos e substâncias que comportem risco para a vida, a qualidade de vida e o meio ambiente;

VI - promover a educação ambiental em todos os níveis de ensino e a conscientização pública para a preservação do meio ambiente;

VII - proteger a fauna e a flora, vedadas, na forma da lei, as práticas que coloquem em risco sua função ecológica, provoquem a extinção de espécies ou submetam os animais a crueldade (BRASIL, 1988).
}

Além do Capítulo VI, dedicado exclusivamente ao meio ambiente, outros artigos da CF/88 trazem também, implícita ou explicitamente, de modo esparso, comandos 
concernentes ao aspecto ambiental no Brasil, como, por exemplo, os artigos 23 e 24, que estabelecem, respectivamente, a competência comum da união, estados, distrito federal e municípios de proteger o meio ambiente e combater a poluição. E, ainda, preservar as florestas, a fauna e a flora, assim como a competência concernente à união, estados e DF para legislar sobre "[...] florestas, caça, pesca, fauna, conservação da natureza, defesa do solo e dos recursos naturais, proteção do meio ambiente e controle da poluição" (BRASIL, 1988).

Destacam-se, assim, dos dispositivos constitucionais, essencialmente do capítulo VI citado, as principais obrigações incumbidas ao poder público, inferindo-se que, desse modo, não só lhe cabe elaborar e implementar políticas ambientais de caráter exógeno, destinadas a regular condutas da coletividade, como também instituir políticas socioambientais no âmbito interno da administração pública, para que tais direitos sejam efetivamente contemplados.

\subsection{A Política Nacional de Recursos Hídricos}

A Política Nacional de Recursos Hídricos, instituída pela Lei no 9.433, de 08 de janeiro de 1997, configura-se, também, como política pública que se incorpora aos demais normativos que compõem o arcabouço ambiental na esfera pública. Isto porque a gestão de recursos hídricos deve contar, além da participação da sociedade, com a do poder público, como esclarece o inciso VI de seu art. 1ㅇ (BRASIL, 1997).

O artigo 2 일 relaciona os objetivos primordiais da Lei $n=9.433 / 97$ :

\footnotetext{
I - assegurar à atual e às futuras gerações a necessária disponibilidade de água, em padrões de qualidade adequados aos respectivos usos;

II - a utilização racional e integrada dos recursos hídricos, incluindo o transporte aquaviário, com vistas ao desenvolvimento sustentável;

III - a prevenção e a defesa contra eventos hidrológicos críticos de origem natural ou decorrentes do uso inadequado dos recursos naturais (BRASIL, 1997).
}

Dentre as diretrizes gerais de ação para implementação desta Política, evidencia-se a de "[...] promover a integração da gestão de recursos hídricos com a gestão ambiental", a qual figura como uma das competências atribuídas ao poder público, nas esferas federal, 
estadual e municipal, conforme apontam os artigos 29 a 31 do capítulo VI, que trata "Da Ação do Poder Público" (BRASIL, 1997).

Perceptível, assim, da generalidade da Lei em tela, a inserção do poder público, ao qual se destina a incumbência da edição de políticas externas destinadas ao adequado gerenciamento hídrico da coletividade e de internalização das práticas de utilização racional de recursos hídricos na estrutura administrativa, compondo um dos eixos de atuação da gestão ambiental pública.

\subsection{A Política Nacional de Educação Ambiental}

A Política Nacional de Educação Ambiental foi instituída pela Lei no 9.795 de 27 de abril de 1999 e soma-se aos demais estruturantes de sistemas públicos de gestão socioambiental. A educação ambiental, de acordo com a definição de seu artigo 1으, caracteriza-se por "[...] processos por meio dos quais o indivíduo e a coletividade constroem valores sociais, conhecimentos, habilidades, atitudes e competências voltadas para a conservação do meio ambiente, bem de uso comum do povo, essencial à sadia qualidade de vida e sua sustentabilidade" (BRASIL, 1999).

Neste contexto, é relevante enumerar os objetivos fundamentais da educação ambiental, constantes do art. 5으 desta Lei:

\footnotetext{
I - o desenvolvimento de uma compreensão integrada do meio ambiente em suas múltiplas e complexas relações, envolvendo aspectos ecológicos, psicológicos, legais, políticos, sociais, econômicos, científicos, culturais e éticos;

II - a garantia de democratização das informações ambientais;

III - o estímulo e o fortalecimento de uma consciência crítica sobre a problemática ambiental e social;

IV - o incentivo à participação individual e coletiva, permanente e responsável, na preservação do equilíbrio do meio ambiente, entendendo-se a defesa da qualidade ambiental como um valor inseparável do exercício da cidadania;

V - o estímulo à cooperação entre as diversas regiões do País, em níveis micro e macrorregionais, com vistas à construção de uma sociedade ambientalmente equilibrada, fundada nos princípios da liberdade, igualdade, solidariedade, democracia, justiça social, responsabilidade e sustentabilidade; [...]

VII - o fortalecimento da cidadania, autodeterminação dos povos e solidariedade como fundamentos para o futuro da humanidade (BRASIL, 1999).
}

As ações têm maior probabilidade de se tornarem efetivas por meio da sensibilização decorrente da educação ambiental, ou seja, a partir do fortalecimento da conscientização 
crítica dos direitos e deveres concernentes à problemática socioambiental, o que, por sua vez, compete à sociedade como um todo e à administração pública.

Neste prisma, a Lei de Educação Ambiental estabelece ao poder público a incumbência de definir políticas públicas que incorporem a dimensão ambiental, bem como promover programas de capacitação aos trabalhadores de instituições públicas, visando à melhoria e ao controle efetivo das repercussões do processo produtivo no meio ambiente (BRASIL, 1999).

Destarte, a educação ambiental não formal, que ocorre distintamente daquela das salas de aula no ensino formal, caracterizada pelas "[...] ações e práticas educativas voltadas à sensibilização da coletividade sobre as questões ambientais e à sua organização e participação na defesa da qualidade do meio ambiente" (BRASIL, 1999), deve ocorrer também no âmbito institucional público, com a sensibilização e conscientização dos agentes públicos, consolidando-se como fundamental na gestão socioambiental pública.

\subsection{Separação de resíduos recicláveis descartados e coleta seletiva}

Somando-se aos demais normativos exarados na esfera federal, o Decreto $\mathrm{n}$ 0 5.940, de 25 de outubro de 2006, representa uma das grandes iniciativas destinadas à inserção de práticas socioambientais na gestão pública. O decreto em comento "[...] institui a separação dos resíduos recicláveis descartados pelos órgãos e entidades da administração pública federal direta e indireta, na fonte geradora, e a sua destinação às associações e cooperativas dos catadores de materiais recicláveis" (BRASIL, 2006).

Em seu art. 2ํㅡ, o documento define "coleta seletiva solidária" e "resíduos recicláveis descartados" e, em seu artigo 3ㅇ, estabelece os requisitos para habilitação de associações e cooperativas de catadores de materiais recicláveis. Ademais, estabelece no art. 50 a necessidade de constituição de comissão para a coleta seletiva solidária no âmbito de cada órgão da administração pública federal e demais providências nos artigos subsequentes (BRASIL, 2006). Assim, esse artigo obriga as instituições públicas da esfera federal a cumprirem essa norma; podendo, entretanto, ser adotada, indistintamente, nas esferas estaduais e municipais de quaisquer poderes. 
Os possíveis reflexos decorrentes da adoção de tal prática podem ser vislumbrados nos aspectos ambientais e sociais, constatando-se, por um lado, resultados ambientalmente sustentáveis com a separação e destinação adequada dos resíduos gerados na gestão pública, e, assim, a diminuição do impacto causado pelos resíduos produzidos. Outro aspecto é a redução da extração e consumo de recursos naturais; por conseguinte, no aspecto social, a destinação dos resíduos a associações e cooperativas de catadores compreende aspectos positivos, como ampliação de oportunidades, aumento da renda familiar e inclusão social de trabalhadores, configurando-se, deste modo, como importante ferramenta socioambiental, que também se insere no arcabouço legislativo e deve ser observada por ocasião da implantação da gestão socioambiental pública.

\subsection{A Política Nacional de Mudança de Clima}

Corroborando com as demais estratégias, a Política Nacional de Mudança de Clima PNMC, instituída pela Lei no 12.187, em 2009, de caráter geral, deve ser observada por ocasião das iniciativas socioambientais no âmbito público. Neste aspecto, o artigo 3ำ é claro ao estabelecer que a "PNMC e as ações dela decorrentes, executadas sob a responsabilidade dos entes políticos e dos órgãos da administração pública, observarão os princípios da precaução, da prevenção, da participação cidadã, do desenvolvimento sustentável e o das responsabilidades comuns" (BRASIL, 2009). Deve ser ressaltado que as medidas adotadas na sua execução deverão considerar, dentre outros aspectos, que "[...] todos têm o dever de atuar, em benefício das presentes e futuras gerações, para a redução dos impactos decorrentes das interferências antrópicas sobre o sistema climático" (BRASIL, 2009).

A PNMC relaciona algumas diretrizes, das quais se salientam as de maior relevância e aplicabilidade no contexto de análise deste estudo, como as ações de mitigação da mudança do clima, em consonância com o desenvolvimento sustentável; as estratégias integradas nos âmbitos local, regional e nacional, com o estímulo e o apoio à participação dos governos federal, estadual, distrital e municipal no desenvolvimento e na execução de políticas, planos, programas e ações relacionados à mudança do clima. E, ainda, a promoção da disseminação de informações, a educação, a capacitação e a conscientização pública sobre 
mudança do clima e o estímulo à promoção de padrões sustentáveis de produção e consumo (BRASIL, 2009).

Além das diretrizes mencionadas, o artigo 11 da Lei no 12.187/2009, vem solidificar a responsabilidade socioambiental no setor público, ao estabelecer que os instrumentos das políticas públicas e programas governamentais deverão compatibilizar-se com os princípios, objetivos, diretrizes e instrumentos da Política Nacional sobre Mudança do Clima (BRASIL, 2009).

Visualiza-se, deste modo, a obrigação da administração pública quanto à observância de critérios socioambientais por ocasião da elaboração e execução de quaisquer políticas ou programas governamentais, percebendo-se de tal mandamento legal a necessidade de adoção de sistemas de gestão ambiental.

\subsection{A Política Nacional de Resíduos Sólidos}

A Política Nacional de Resíduos Sólidos - PNRS - foi instituída pela Lei № 12.305, de 2 de agosto de 2010, e se incorpora ao rol legislativo das práticas a serem observadas inclusive pela esfera pública, com vistas à implantação de gestões socioambientais.

A PNRS integra a Política Nacional do Meio Ambiente e articula-se com a Política Nacional de Educação Ambiental, e, de acordo com o seu artigo 4으, reúne princípios, objetivos, instrumentos, diretrizes e ações adotados pelo governo federal com vistas à gestão e gerenciamento ambientalmente adequado dos resíduos sólidos (BRASIL, 2010).

Além disso, a Lei № 12.305/2010 elenca, em seu art. 7으, quais são os objetivos da Política Nacional de Resíduos Sólidos, os quais se transcrevem:

I - proteção da saúde pública e da qualidade ambiental;

II - não geração, redução, reutilização, reciclagem e tratamento dos resíduos sólidos, bem como disposição final ambientalmente adequada dos rejeitos;

III - estímulo à adoção de padrões sustentáveis de produção e consumo de bens e serviços; [...]

VIII - articulação entre as diferentes esferas do poder público, e destas com o setor empresarial, com vistas à cooperação técnica e financeira para a gestão integrada de resíduos sólidos; [...]

$X$ - regularidade, continuidade, funcionalidade e universalização da prestação dos serviços públicos de limpeza urbana e de manejo de resíduos sólidos, [...]

(Continua) 
XI - prioridade, nas aquisições e contratações governamentais, para:

a) produtos reciclados e recicláveis;

b) bens, serviços e obras que considerem critérios compatíveis com padrões de consumo social e ambientalmente sustentáveis;

XII - integração dos catadores de materiais reutilizáveis e recicláveis nas ações que envolvam a responsabilidade compartilhada pelo ciclo de vida dos produtos; [...]

XIV - incentivo ao desenvolvimento de sistemas de gestão ambiental e empresarial voltados para a melhoria dos processos produtivos e ao reaproveitamento dos resíduos sólidos, incluídos a recuperação e o aproveitamento energético [...] (BRASIL, 2010).

Desta maneira, suscintamente, o setor público, na implementação da responsabilidade socioambiental em sua estrutura interna, deverá observar os objetivos citados, a partir dos quais deverá visar, principalmente: à ampliação da qualidade ambiental; à não geração, redução, reutilização, reciclagem e tratamento dos resíduos sólidos; à adoção de padrões sustentáveis de produção e consumo de bens e serviços; à prioridade, nas aquisições e contratações governamentais, de produtos reciclados e recicláveis e de bens, serviços e obras que considerem critérios compatíveis com padrões de consumo social e ambientalmente sustentável.

\subsection{Contratações públicas sustentáveis}

A administração pública, em seu desiderato, deve observar os princípios consagrados em capítulo específico da CF/1988, constantes do artigo 37: legalidade, impessoalidade, moralidade, publicidade e eficiência (BRASIL, 1988) e, além disso, obedecer aos preceitos relacionados nos incisos seguintes, dos quais interessa transcrever o contido no inciso XXI, que trata das licitações públicas:

\footnotetext{
XXI - ressalvados os casos especificados na legislação, as obras, serviços, compras e alienações serão contratados mediante processo de licitação pública que assegure igualdade de condições a todos os concorrentes, com cláusulas que estabeleçam obrigações de pagamento, mantidas as condições efetivas da proposta, nos termos da lei, o qual somente permitirá as exigências de qualificação técnica e econômica indispensáveis à garantia do cumprimento das obrigações (BRASIL, 1988).
}

Visando à ampliação e regulamentação do inciso XXI da CF/1988, foi sancionada, em 1993, a Lei $n$ ㅇ 8.666, a qual institui normas para licitações e contratos da administração pública. (BRASIL, 1993). 
A Lei das Licitações, em seu texto original, não fazia qualquer alusão ao que diz respeito aos critérios de sustentabilidade nas compras públicas. Ocorre que, com a edição da Lei $\mathrm{n}$ o $12.349 / 2010$, tal critério passou a compor o rol de princípios norteadores dessas licitações, conforme se verifica da nova redação do artigo 3으 da Lei no 8.666/93:

Art. 3ำ A licitação destina-se a garantir a observância do princípio constitucional da isonomia, a seleção da proposta mais vantajosa para a administração e a promoção do desenvolvimento nacional sustentável e será processada e julgada em estrita conformidade com os princípios básicos da legalidade, da impessoalidade, da moralidade, da igualdade, da publicidade, da probidade administrativa, da vinculação ao instrumento convocatório, do julgamento objetivo e dos que lhes são correlatos (BRASIL, 1993, grifo nosso).

Do exposto acima, identifica-se o dever estabelecido ao gestor público quanto à observância da adoção do critério da sustentabilidade nas compras e contratações públicas nos poderes da união, estados, distrito federal e municípios, visto que a Lei no 8.666/93 é aplicável a todas as esferas especificadas.

No âmbito da administração pública federal, contudo, para a maximização da aplicabilidade da nova exigência licitatória, editaram-se dois instrumentos, a Instrução Normativa 01/2010 do MPOG e o Decreto no 7.746 de 05 de junho de 2012, regulamentando o art. 3으 da Lei no 8.666/93 e estabelecendo critérios, práticas e diretrizes para a promoção do desenvolvimento nacional sustentável por ocasião de suas contratações (BRASIL, 2012).

Neste sentido, então, o primeiro, editado pelo Ministério do Planejamento, Orçamento e Gestão, "[...] dispõe sobre os critérios de sustentabilidade ambiental na aquisição de bens, contratação de serviços ou obras pela Administração Pública Federal" (MPOG, 2010).

No Decreto no 7.746/2012, verificam-se, no art. 4으, as diretrizes de sustentabilidade pleiteadas por ocasião das contratações, tais como a busca pelo menor impacto sobre os recursos naturais, maior eficiência na utilização de recursos naturais como água e energia, uso de inovações que reduzam a pressão sobre esses recursos, bem como a origem ambientalmente regular dos recursos naturais utilizados nos bens, serviços e obras (BRASIL, 2012).

Destaca-se ainda deste documento o dever de instituição de comissões de sustentabilidade na administração pública, as quais, de acordo com o art. 9o, têm por finalidade a implementação de critérios, práticas e ações de logística sustentável no âmbito 
da administração pública federal (BRASIL, 2012), atribuindo as competências previstas em seu artigo 11:

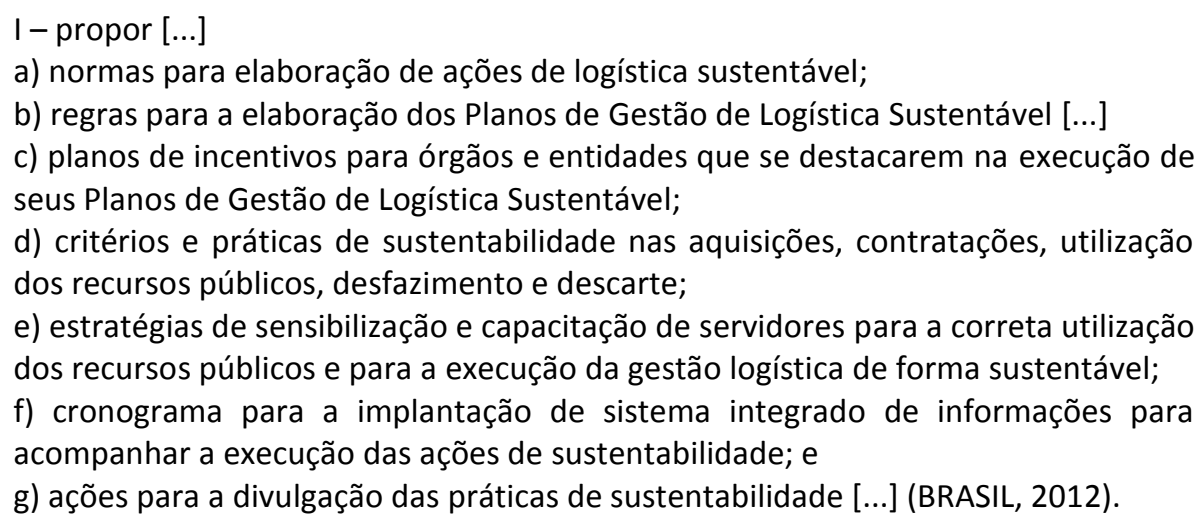

Outro aspecto relevante dessa ferramenta de gestão socioambiental é o decorrente do art. 16, que dita a obrigatoriedade de elaboração e implementação, dentro do prazo definido, de Planos de Logística Sustentável no âmbito da administração pública federal direta, autárquica e fundacional (BRASIL, 2012).

Com o exposto, confirma-se a relevância dessas políticas aplicadas às compras e contratações públicas, possibilitando a obtenção de resultados positivos, despontando, deste modo, como um dos aspectos essenciais de gestão socioambiental pública.

\subsection{O Plano de Logística Sustentável}

O Plano de Logística Sustentável - PLS - surge como inovador instrumento de gestão socioambiental, o qual vem sendo implementado paulatinamente na administração pública federal desde a sua previsão no ano de 2012.

A obrigatoriedade de sua implementação deu-se, inicialmente, com o Decreto Federal no 7.746 de 2012, o qual, em seu artigo 16, dispôs do seguinte modo: “A administração pública federal direta, autárquica e fundacional e as empresas estatais dependentes deverão elaborar e implementar Planos de Gestão de Logística Sustentável, no prazo estipulado pela Secretaria de Logística e Tecnologia da Informação [...]" (BRASIL, 2012).

A Secretaria de Logística e Tecnologia da Informação do MPOG estabeleceu as regras concernentes à elaboração dos PLS, com a edição da Instrução Normativa no 10, de 12 de novembro de 2012. 
Os PLS correlacionam os critérios ambientais aos de eficiência e economicidade e, conforme o art. 3ㅇ da IN 10/2012, “[...] são ferramentas de planejamento com objetivos, responsabilidades, ações, metas, prazos de execução e mecanismos de monitoramento e avaliação, que permitem ao órgão estabelecer práticas de sustentabilidade e racionalização de gastos e processos na Administração Pública" (MPOG, 2012).

Alguns temas deverão constar dos PLS, e, como reza o art. 50 da referida normativa, no mínimo os seguintes:

I - atualização do inventário de bens e materiais do órgão ou entidade e identificação de similares de menor impacto ambiental para substituição;

II - práticas de sustentabilidade e de racionalização do uso de materiais e serviços;

III - responsabilidades, metodologia de implementação e avaliação do plano; e

IV - ações de divulgação, conscientização e capacitação (MPOG, 2012).

Assim, em referência às práticas de sustentabilidade e racionalização no uso de materiais e serviços, a IN 10/2012, em seu art. 8으, apresenta uma lista não exaustiva, mas cujos temas deverão ser contemplados minimamente, conforme transcrito:

\footnotetext{
I - material de consumo compreendendo, pelo menos, papel para impressão, copos descartáveis e cartuchos para impressão;

II - energia elétrica;

III - água e esgoto;

IV - coleta seletiva;

$\mathrm{V}$ - qualidade de vida no ambiente de trabalho;

VI - compras e contratações sustentáveis, compreendendo, pelo menos, obras, equipamentos, serviços de vigilância, de limpeza, de telefonia, de processamento de dados, de apoio administrativo e de manutenção predial; e

VII - deslocamento de pessoal, considerando todos os meios de transporte, com foco na redução de gastos e de emissões de substâncias poluentes (MPOG, 2012).
}

Destaque especial deve ser dado à dinâmica concedida pela norma à implantação das iniciativas e práticas, visto que, para cada tema do PLS, há a exigência de criação de planos de ação, com a identificação dos objetivos, detalhamento, unidades ou áreas envolvidas, metas, cronograma de implantação e previsão de recursos financeiros, humanos e outros para a implementação das ações, bem como monitoramento e avaliação de resultados (MPOG, 2012).

Por fim, outro aspecto destacável da sistemática de implantação do PLS é o que estabelece o dever de publicação semestral, em site dos respectivos órgãos (MPOG, 2012), 
das metas alcançadas e resultados obtidos, conferindo ao processo a característica da boa gestão pública, consubstanciada pela transparência e prestação de contas à sociedade.

Constata-se que este é um ponto forte dentre os demais normativos que compõem o arcabouço legislativo que caracteriza a gestão socioambiental pública, tendo em vista que, de certa forma, inova com a exigência da implantação efetiva de ações que podem repercutir positivamente na adoção de critérios de sustentabilidade e responsabilidade socioambiental.

Conclui-se, deste modo, a apresentação dos resultados e respectivas discussões que nortearam o estudo, por meio da compilação, identificação e análise dos principais instrumentos legais e dos respectivos dispositivos de caráter socioambiental, orientados à esfera pública brasileira, especificamente ao âmbito operacional e administrativo interno.

Todos os normativos relacionados ditam as diretrizes gerais, que orientam a adoção de iniciativas ambientais, embora se tenha que ressaltar que os distintos órgãos componentes dos três poderes (Executivo, Legislativo e Judiciário), nas instâncias municipal, estadual e federal, têm suas peculiaridades e podem, a partir daqueles parâmetros gerais, elaborar e implementar os próprios instrumentos de gestão socioambiental por meio de portarias, regulamentos, instruções normativas ou programas que atendam às suas particularidades.

\section{Considerações finais}

A problemática ambiental, com todos os seus impactos sociais e ambientais, tornouse evidente, essencialmente, a partir da década de 1960 e, desde então, assumiu proporções que, na atualidade, representam riscos à vida no planeta. Diante deste cenário, tomaram corpo a preocupação, os movimentos ambientais e os debates mundiais, com vistas à busca de alternativas para a conservação do meio ambiente.

Para além deste debate em nível macro, é indispensável, porém, a superação da discussão teórica, partindo-se para a adoção e incorporação de práticas que minimizem ou eliminem os impactos e a degradação ambiental decorrentes da ação antrópica, o que deve ocorrer por meio da individualização de iniciativas socioambientais em nível micro, inclusive com o envolvimento de organizações ou instituições na esfera pública. 
Para que tais práticas se tornem efetivas, são necessárias ferramentas para a operacionalização de ações na esfera pública, materializadas por meio de instrumentos de gestão ambiental, classificados como instrumentos de comando e controle (SEIFFERT, 2014).

Neste contexto, este estudo objetivou uma análise dos instrumentos socioambientais específicos, aplicáveis internamente às instituições públicas, pois estas, em razão de suas atribuições, constituem-se grandes consumidores de bens e serviços e, na mesma proporção, geradores de impactos ambientais, tendo, destarte, o dever de instituir políticas ambientalmente sustentáveis.

Compilaram-se, assim, além dos preceitos contidos na Constituição Federal de 1988, os mais evidentes instrumentos legislativos federais do Brasil de caráter socioambiental, tais como a Política Nacional de Meio Ambiente, a Política Nacional de Recursos Hídricos, a Política Nacional de Educação Ambiental, a Política Nacional de Mudança de Clima, a Política Nacional de Resíduos Sólidos, bem como os normativos referentes à separação de resíduos recicláveis descartados e a coleta seletiva, às contratações públicas sustentáveis e à implantação de Planos de Logística Sustentável na administração pública.

Infere-se da análise que há um arcabouço legislativo capaz de fornecer ao gestor as alternativas e ferramentas para supressão e minimização dos impactos ambientais no âmbito interno público, embora, por si só, esta compilação de instrumentos ambientais não seja capaz de transformar o cenário insustentável.

A gestão socioambiental pública, em que pese ser de ordem imperativa, somente poderá ser efetiva a partir de um conjunto de ações que ultrapasse o aspecto burocrático, frio e estático das leis e normas, com a adoção de postura proativa e comprometida de gestores públicos.

Tal postura compreende a incorporação de práticas como, dentre outras, a adequada capacitação e sensibilização de todos os envolvidos no processo socioambiental; a participação social, com o envolvimento em todas as fases do processo; a transparência e prestação de contas à sociedade, com a ampla disponibilização e publicação de informações correlatas aos impactos causados e políticas empreendidas para a sua supressão ou minimização.

As iniciativas públicas devem, portanto, configurar-se por meio da gestão socioambiental pública, visto que devem contar fortemente com a participação dos variados 
atores sociais em atendimento ao preceituado na $\mathrm{CF} / 1988$, que impõe ao poder público e à coletividade o dever de defender e preservar o meio ambiente, pleiteando, deste modo, a ampliação da qualidade socioambiental para as presentes e futuras gerações.

\section{Referências}

ACSELRAD, Henri; MELLO, Cecília C. do A.; BEZERRA, Gustavo das N. O que é justiça ambiental. Rio de Janeiro: Garamond, 2009.

ALEXANDRINO, Marcelo; PAULO, Vicente. Direito Administrativo Descomplicado. 17. ed. rev. atual. e ampl. Rio de Janeiro: Forense; São Paulo: Método, 2009.

BRAGA, B. et al. Introdução à Engenharia Ambiental. 2. ed. São Paulo: Pearson Prentice Hall, 2005.

BRASIL. Constituição. Constituição da República Federativa do Brasil. 1988. Brasília. Texto publicado no DOU em 5.10.1988. Disponível em: <http://www.planalto.gov.br/ccivil_03/ constituicao/ConstituicaoCompilado.htm>. Acesso em: 11 jun. 2016.

Decreto $n$ o 5.940/2006. Institui a separação dos resíduos recicláveis descartados pelos órgãos e entidades da administração pública federal direta e indireta, na fonte geradora, e a sua destinação às associações e cooperativas dos catadores de materiais recicláveis, e dá outras providências. DOU de 26/10/2006. Disponível em: <http://www.planalto.gov.br/ccivil_03/_Ato2004-2006/2006/Decreto/D5940.htm>. Acesso em: 24 abr. 2016.

Decreto $n$ o 7.746/2012. Regulamenta o art. $3^{\circ}$ da Lei $n^{\circ} 8.666$, de 21 de junho de 1993, para estabelecer critérios, práticas e diretrizes para a promoção do desenvolvimento nacional sustentável nas contratações realizadas pela administração pública federal, e institui a Comissão Interministerial de Sustentabilidade na Administração Pública - CISAP. DOU de 06/06/2012. Disponível em: <http://www.planalto.gov.br/CCIVIL_03/_Ato20112014/2012/Decreto/D7746.htm>. Acesso em: 28 abr. 2016.

Lei no 12.187/2009. Institui a Política Nacional sobre Mudanças do Clima - PNMC e dá outras providências. DOU de 30/12/2009. Edição extra. Disponível em: <http://www.planalto.gov.br/ccivil_03/_Ato2007-2010/2009/Lei/L12187.htm>. Acesso em: 25 abr. 2016.

Lei no 12.305/2010. Institui a Política Nacional de Resíduos Sólidos; altera a Lei $\mathrm{n}^{\circ}$ 9.605, de 12 de fevereiro de 1998; e dá outras providências. DOU de 03/08/2010. Disponível em: <http://www.planalto.gov.br/ccivil_03/_Ato2007-2010/2010/Lei/ L12305.htm>. Acesso em: 24 abr. 2016. 
Lei no 6938/1981. Dispõe sobre a Política Nacional do Meio Ambiente, seus fins e mecanismos de formulação e aplicação, e dá outras providências. DOU de 02/09/1981. Disponível em: <http://www.planalto.gov.br/ccivil_03/Leis/L6938.htm>. Acesso em: 21 jun. 2016.

Lei no 8.666/1993. Regulamenta o art. 37, inciso XXI, da Constituição Federal, institui normas para licitações e contratos da Administração Pública e dá outras providências. DOU de 22/06/1993. Disponível em: <http://www.planalto.gov.br/ccivil_03/Leis/ L8666compilado.htm>. Acesso em: 26 abr. 2016.

Lei no 9.433/1997. Institui a Política Nacional de Recursos Hídricos, cria o Sistema Nacional de Gerenciamento de Recursos Hídricos, regulamenta o inciso XIX do art. 21 da Constituição Federal, [...]. DOU de 09/01/1997. Disponível em: <http://www.planalto.gov.br/ccivil_03/Leis/L9433.htm>. Acesso em: 23 abr. 2016.

Lei no 9.795/1999. Dispõe sobre a educação ambiental, institui a Política Nacional de Educação Ambiental e dá outras providências. DOU de 28/04/1999. Disponível em: <http://www.planalto.gov.br/ccivil_03/Leis/L9795.htm>. Acesso em: 23 abr. 2016.

COMISSÃO MUNDIAL SOBRE MEIO AMBIENTE E DESENVOLVIMENTO. Nosso Futuro Comum. 2. ed. Rio de Janeiro: Fundação Getúlio Vargas, 1991.

FLORIT, L. Teoria social e relação sociedade/natureza a partir da obra de Anthony Giddens. In: Cadernos de sociologia, PPGsociologia/UFRGS, n. 10, 1998, p. 61-86, 1998.

GUIMARÃES, R. A ética da sustentabilidade e a formulação de políticas de desenvolvimento. In: VIANA, G; SILVA, MARINA; DINIZ, N. (Orgs). O desafio da sustentabilidade: um debate socioambiental no Brasil. São Paulo: Fundação Perseu Abramo, 2001. p. 43-68.

JACOBI, Pedro. Educação ambiental, cidadania e sustentabilidade. Cadernos de Pesquisa, São Paulo, n. 118, p. 189-205, março, 2003.

LEFF, Enrique. Aventuras da epistemologia ambiental: da articulação das ciências ao diálogo de saberes. Tradução de Silvana Cobucci Leite. São Paulo: Cortez, 2012.

Complexidade, interdisciplinaridade e saber ambiental. In: Olhar de professor. Ponta Grossa, n. 14, v. 2, p. 309-335, 2011. Disponível em: <http://www.revistas2.uepg.br/index.php/olhardeprofessor>. Acesso em: 14 jul. 2015. Epistemologia ambiental. Tradução: Sandra Valenzuela. 5. ed. São Paulo: Cortez, 2010.

Saber ambiental: sustentabilidade, racionalidade, complexidade, poder. Tradução de Lúcia Mathilde Endlich Orth. Petrópolis: Vozes, 2001. 
LENZA, Pedro. Direito constitucional esquematizado. 13. ed. rev., atual. e ampl. São Paulo: Saraiva, 2009.

MMA - Ministério do Meio Ambiente. Agenda Ambiental na Administração Pública - A3P. 5. ed. revista e atualizada. Brasília, DF: MMA/Secretaria de Articulação Institucional e Cidadania Ambiental/Departamento de Cidadania e Responsabilidade Socioambiental, 2009. Disponível em: <http://www.mma.gov.br/images/arquivo/80063/ cartilha\%20completa\% 20A3P.pdf>. Acesso em: 21 jun. 2016.

MORAN, E. F. O desafio de pesquisa em interações homem-ambiente. In: MORAN, E. F. Meio Ambiente e Ciências Sociais: interações homem-ambiente e sustentabilidade. São Paulo: SENAC, 2011. p. 21-53.

MPOG. Ministério do Planejamento, Orçamento e Gestão. Instrução Normativa no 1 , de 19 de janeiro de 2010. Disponível em: <http://www.comprasgovernamentais.gov.br/ paginas/instrucoes-normativas/instrucao-normativa-no-01-de-19-de-janeiro-de-2010>. Acesso em: 4 maio 2016.

. Instrução Normativa no 10, de 12 de novembro de 2012. Disponível em: <http://www.comprasgovernamentais.gov.br/paginas/instrucoes-normativas/instrucaonormativa-no-10-de-12-de-novembro-de-2012>. Acesso em: 9 maio 2016.

SABBAGH, Roberta B. Gestão ambiental. Cadernos de Educação Ambiental, 16. São Paulo (Estado). Secretaria do Meio Ambiente. São Paulo: SMA, 2011. Disponível em: <http://www.ambiente.sp.gov.br/wp-content/uploads/2011/10/16-GestaoAmbiental.pdf>. Acesso em: 8 jun. 2016.

SEIFFERT, Mari Elizabete B. Gestão ambiental: instrumentos, esferas de ação e educação ambiental. 3. ed. São Paulo: Atlas, 2014.

SILVA, Carlos E. M. Desenvolvimento Sustentável. In: CALDART, Roseli; PEREIRA, Isabel; ALENTEJANO, Paulo; FRIGOTTO, Gaudêncio (Orgs.). Dicionário da Educação do Campo. Rio de Janeiro/São Paulo: Escola Politécnica de Saúde Joaquim Venâncio/Expressão Popular, 2012. 